\title{
Supporting failing students: how collaboration is key
}

\begin{abstract}
Current NMC Standards state that the balance between clinical practice and theory in pre-registration midwifery programmes must be no less than $50 \%$ practice and no less than $40 \%$ theory, with students being supported by 'midwife teachers' and 'midwife mentors' (NMC, 2009:18). Midwife teachers are expected to be involved in learning and assessment in both academic and practice learning environments by engaging in activities such as link tutoring; facilitating mentor development and updates; having a part-time clinical role or being involved with practice development, midwives' CPD or practice-based research activities.

Clinical practice is supervised and graded by sign-off mentors, aka 'gatekeepers to the profession' (Peat, 2018:355) who confirm students are clinically competent, commensurate with their level of training, and at the end of their 3year programme of study are fit for entry to the midwives' part of the register.

This article will consider the importance of a collaborative approach between universities and clinical placement providers, particularly in relation to supporting failing students as whilst there has to be the recognition that some students need to fail' (Duffy, 2003:83) sometimes students just require more focussed support and action planning to achieve the required skills, competencies and confidence in practice.
\end{abstract}

Keywords: sign-off mentor; personal academic tutor; competence; collaboration; failure to fail

\section{Introduction}

At the University of Northampton (UoN) the role of the midwife teacher/academic in relation to the assessment of clinical practice is to provide advice and support to mentors, with the ultimate decision on whether the student is competent in practice being the sign-off mentor's decision (see box 1). Watson and Harris (1999:51) found that many mentors in their study did not understand or realise that grading was their responsibility, with one participant stating 'I don't think we can actually fail assessments. We can only put down what we feel, and if we're not happy, I think it's up to the college then to decide if they've actually failed their placement or not'. It is therefore not surprising that the study also identified that mentors were sometimes 'failing to fail', with 125 mentors out of 272 $(n=46 \%)$ agreeing with the suggestion that students were sometimes allowed to pass practice placement assessments when in fact their performance was unsatisfactory. 


\section{Criteria for a sign-off mentor:}

Sign-off mentors that are on the same part of the register and in the same field of practice may confirm that students have met the relevant standards of proficiency for the particular programme leading to registration or a qualification that is recordable on the NMC register.

Placement providers must ensure that a nurse or midwife designated to sign-off proficiency for a particular student at the end of a programme is:

- Identified on the local register as a sign-off mentor or a practice teacher

- Registered on the same part of the register

- Working in the same field of practice as that in which the student intends to qualify

Additionally to be a sign-off mentor they must have:

- Clinical currency and capability in the field in which the student is being assessed

- A working knowledge of current programme requirements, practice assessment strategies and relevant changes in education and practice for the student they are assessing

- An understanding of the NMC registration requirements and the contribution they make to the achievement of these requirements

- An in-depth understanding of their accountability to the NMC for the decision they must make to pass or fail a student when assessing proficiency requirements at the end of a programme

- Been supervised on at least three occasions for signing off proficiency by an existing sign-off mentor

- A working knowledge of current programme requirements, practice assessment strategies and relevant changes in education and practice for the student they are assessing

- The achievement of these requirements

- An understanding of the NMC registration requirements and the contribution they make to meeting these requirements

- An in-depth understanding of their accountability to the NMC for the decision they make to pass or fail

(NMC, 2008:27)

Box 1

In 2003 Duffy conducted a qualitative study to explore why some student nurses were passed in practice without having demonstrated 'sufficient competence'. Her findings (box 2) were supported in a more recent literature review which identified the following key themes:

- Difficulties in assessing a student's attitude

- The subjective nature of assessment

- 'Benefit of the doubt' culture

- Perceived lack of support when failing a student 
- Confidence to make a decision to fail a student

(Elliott, 2016:251)

Duffy's recommendations are transferable to midwifery education, included the need for more input in mentor updates on how to deal with failing students in terms of the formal processes to follow; the importance of early identification of failing students and the support mechanisms in place for mentors, both from academics and managers. The introduction of tripartite meetings in practice as part of the clinical assessment process was identified as key to maintaining good channels of communication between approved educational institutions and clinical placement providers; thereby ensuring mentors and students are well supported. Elliott again concurs, identifying early identification and effective management of failing students based on an open, honest and professional student/mentor relationship as key to a successful outcome.

\section{Key Findings:}

- Mentors' verbal concerns were not always acted upon by academics and so they did not feel supported in their role ie 'why bother?'

- Some mentors were reluctant to document their concerns and so gave students 'the benefit of the doubt' - consequently some students were in their final year before being identified as failing - putting additional emotional pressures on mentors perceived as 'ending students' careers' at the final hurdle

- Some mentors felt the practice assessment documents were ambiguous and could contribute to the issue of 'failing to fail'

- If due process in terms of timely identification of issues and appropriate action planning and documentation was not followed this could negatively impact on academics feeling able to support mentors to fail students

- Failing students is time consuming and mentors did not feel supported by managers, with staff shortages, lack of time and increasingly complex caseloads contributing to the perception of 'not having time' to fail students

- Mentor updates did not address the issue of 'failing to fail' therefore mentors did not feel adequately prepared for this difficult role, which was particularly anxiety provoking for underconfident mentors

- Mentors' decisions not to fail students were sometimes influenced by students' personal situations ie they felt sorry for them

- Failure to fail on attitude grounds was an area of frustration for academics as they felt that these attributes were not given equal weighting with clinical competencies

- With the move into higher education, clinical grades could sometimes excessively inflate final classifications and there was a tension between maintaining professional standards and student retention

(Duffy, 2003) 


\section{The Academic's Perspective}

Currently students have 3 discrete placement areas per year: community, labour ward and the antenatal/postnatal wards, with sign-off mentors in each area grading students' practice. There is a formal mid-placement review/tripartite meeting for each placement with either the Personal Academic Tutor (PAT) or SLiP (Senior Lecturer in Practice). Informal support is offered throughout the placement, with mentors and students being encouraged to contact either the PAT or SLiP if they have concerns at any point. The rationale for the mid-placement review is to provide an opportunity for the student, mentor and academic to discuss the student's progress thus far and identify whether the mentor feels the student is on track to achieve all required clinical skills and competencies by the end of the placement. If the mentor and/or student voice concerns then a learning development plan is put in place with a focus on areas requiring targeted support. If a student does not meet the requirements of their learning development plan and practiced assessment document they will be referred at first opportunity and a formal Action Plan will be put in place for their second opportunity.

UoN's clinical practice support model follows Duffy's (2003) recommendations of comprehensive support for mentors during mentor updates and throughout clinical placements. Mid- placement reviews along with an 'open door' policy for dialogue between academics, mentors and students promote an environment of mutual respect, open communication and collaboration.

\section{The Clinician's Perspective}

Working with students who are underperforming in practice can be extremely stressful, particularly as working closely together over an extended period means a relationship will have developed. There is an investment in them succeeding and the mentor can sometimes feel that the success or failure of a student is a reflection on their ability to teach. However, failing to fail underperforming students leads to risk: risk to the lives of women and their babies and risk to their colleagues who expect them to be practice safely and competently. Not failing a student also means that the student does not have the opportunity to be the best that they can be.

\section{Top Tips for supporting all students in practice:}

- At the start of any placement always refer to the student's Ongoing Record of Achievement (ORA) as this is effectively a 'hand over' sheet from previous mentors, identifying strengths and areas for development

- Give regular (ideally every shift) constructive feedback so there are no 'surprises' at the end of the placement 
- Mid-placement reviews/tripartites are a forum for an honest and open discussion between mentor, student and PAT/SLiP

\section{Additional Tips for supporting underperforming students in practice:}

- Inform the student's PAT and SLiP as soon as you have any concerns with a student's practice so that a meeting can be arranged to co-create a learning plan for the rest of the placement

- State clearly, in writing, what you expect and how the student can achieve this

- There should be regular contact between the PAT/SLiP and sign-off mentor and student for the rest of the placement to monitor progress

- If you refer a student, clearly document the learning objectives/competencies/clinical skills that have not been achieved and give examples so that the student and subsequent mentors are clear on areas to focus on during the second opportunity placement

- If a student is referred then the same approach to support should be adopted for the second opportunity

\section{The benefits of a collaborative approach}

By adopting a collaborative approach between PAT/SLiP and sign-off mentor to supporting students in practice, the perceived 'theory-practice' gap is closed; mentors feel more supported, particularly when working with an underperforming student; there is open dialogue between student, university and placement provider and ultimately women and their families will receive care from well trained, competent and confident midwives.

The Code (NMC, 2015) requires midwives to have a professional 'duty of candour', meaning they are duty bound to raise any concerns they have in practice which might put the women and babies in their care at risk. They also have an obligation to be a 'model of integrity and leadership' (NMC, 2015:15) and in the context of mentoring this includes carrying out the very challenging task of failing underperforming students. For students who subsequently pass a second opportunity placement, repeating can be a positive experience as it allows the student to develop their skills and confidence; consolidate what they have learned and develop a richer, more in depth knowledge base. It also requires them to develop their resilience, which is a key attribute of confident and competent midwives in today's maternity services (Hunter and Warren, 2013). For students who subsequently fail a second opportunity placement, the mentor should look to the Code for reassurance that they have acted appropriately in order to preserve the safety of the public and the reputation of their profession and remember that despite their best efforts 'there has to be the recognition that some students need to fail' (Duffy, 2003:83). 


\section{References}

Duffy K (2003) Failing students: a qualitative study of factors that influence the decisions regarding assessment of students' competence in practice. Glasgow: Caledonian University: Department of Nursing and Community Health

Elliott C (2016) Identifying and managing underperformance in nursing students. British Journal of Nursing 25 (5) 250-255

Hunter B, Warren L. (2013) Investigating Resilience in Midwifery: Final report. Cardiff University: Cardiff

Nursing and Midwifery Council (NMC) (2008) Standards to support learning and assessment in practice. London: NMC

Nursing and Midwifery Council (NMC) (2009) Standards for pre-registration midwifery education. London: NMC

Peate I (2018) Failing to fail. British Journal of Nursing 27 (7) 355

Watson H, Harris B (1999) Supporting Students in Practice Placements in Scotland. Glasgow Caledonian University: Department of Nursing and Community Health

\section{Authors}

Alison Power (Senior Lecturer - Midwifery)

Olivia Albaradura (Community Midwife Team Leader, Milton Keynes University Hospital, NHS Foundation Trust) 